\title{
Improving wrist imaging through a multicentre educational intervention: the challenge of orthogonal projections
}

\section{Authors:}

Beverly Snaith, Scott Raine, Lynsey Fowler, Christopher Osborne, Sophie House, Ryan Holmes, Emma Tattersall, Emma Pierce, Melanie Dobson, James W Harcus,

\section{Introduction}

The wrist is a complex anatomical region and outside of carpal articulations the ulna provides stability, with pronation and supination facilitated by rotation and sliding against the radius at the proximal and distal radioulnar joints (DRUJ)..$^{1-3}$ The incidence of wrist fractures is rising, ${ }^{4,5}$ with sports injuries, road traffic collisions and falls representing the most common mechanisms. Despite reservations about the sensitivity of radiography for some fracture types, ${ }^{6}$ it remains the primary imaging modality. ${ }^{7}$ However key to its utility is the quality of imaging examinations and assurance that the images accurately demonstrate the patient's anatomy.

In relation to imaging, orthogonal projections should be obtained, ${ }^{8}$ with (a minimum of) two radiographs obtained at $90^{\circ} .{ }^{9-11}$ For the wrist, this consistent of a postero-anterior (PA), sometimes referred to as a dorsi-palmar (DP) view, and a lateral projection. This enables assessment of the bony anatomy and radio-ulna joint congruity. The wrist should be imaged in a neutral position so as not to placing the DRUJ under stress ${ }^{12}$ and the whole limb rotated for the lateral projection to avoid isolated radial rotation. ${ }^{9,11,13}$ However, this principle is not universally applied. Shin et al ${ }^{13}$ identified the issue, citing several publications showing images with identical ulna orientation on the two projections. Such examples ${ }^{11,13}$ suggest that inconsistent positioning standards are an international issue, but it is unclear whether it relates to local accepted practice and/or a lack of understanding of anatomy.

No previous study has examined wrist positioning at scale. This article reports on a multicentre initiative to evaluate the accuracy of radiographic position and clinical practice compliance with the orthogonal principles. An educational intervention was subsequently undertaken, and longitudinal evaluation performed.

\section{Method}

The setting for this multiphase study was five NHS Trusts in northern England, with data collected across eight different hospital sites. All organisations are district general hospitals with some limited tertiary facilities and are spread over a 70-mile radius. This study used the premise that the positioning described in the most common UK imaging practice textbooks ${ }^{14,15}$ and in the scientific literature would result in two orthogonal images. For the PA projection the shoulder is abducted to $90^{\circ}$ and the elbow placed in $90^{\circ}$ of flexion with the wrist pronated. This should be supplemented by a lateral with the arm extended and the wrist rotated to superimpose the radius and ulna. 
As this was an assessment of current practice, it was considered service evaluation and did not require ethical approval. All images were reviewed at a site level by experienced radiographers who were employees of the host organisation. No images or identifiable patient data transferred between sites. The patient characteristics and referral information collected including age, gender, clinical history, outcome and image appearances. To identify any bias in sampling the details of the individual performing the imaging examination was collected, anonymity was assured by assigning a unique code to each operator (at a site level). Where a student radiographer had performed the examination the code of the supervising radiographer was recorded.

Baseline (pre-intervention) evaluation

Using a random number generator three different dates were determined over a three-month period (July-September 2017). All patients attending for wrist or scaphoid radiographs within the 24hour period were identified from the local radiology information system. Images were reviewed on picture archive and communication system (PACS) in appropriate lighting conditions.

The examinations included in the review were wrist and/or scaphoid radiographs of any patient age or referral groups. Scaphoid radiographs were included as two of the standard projections are the identical to the wrist examination. Exclusion criteria were forearm examinations, radiographs demonstrating wrist immobilisation (plaster cast or splint) or surgical intervention within the preceding three months, as these factors may have resulted in adaptation to standard techniques.

\section{Educational intervention}

Following review of the baseline outcomes a low-intensity passive intervention was designed. The intervention comprised a laminated A3 poster that was prominently displayed in staff clinical areas. The poster described the correct and inappropriate techniques and included relevant photographs and radiographs (supplementary figure 1). The site-based authors provided an explanation of the purpose of the intervention and answered questions posed by staff. No information was provided regarding the prospective re-evaluation, of which staff were unaware. This approach is consistent with ongoing quality assurance processes in imaging with regular analysis of rejected and approved radiographic projections and ongoing education programmes.

\section{Post-intervention evaluation}

To measure the impact of the intervention further evaluation took place at two-weeks (early) and three-months (late). For each of these reviews the sample comprised two randomly selected days within a single week using a random number table. All wrist and scaphoid radiographs were assessed for any initial and sustained change in practice, with the baseline data collection methods repeated.

\section{Statistical analysis}

Data were collated in Excel (Microsoft) for descriptive analysis. Further statistical analysis was performed in SPSS (V25.0) including analysis of variance (ANOVA) for comparison of mean age and Chi squared for test of proportions between samples. Fisher's exact test enabled the comparison of compliance with the standard between phases. For all statistics the significance level was 0.05 .

No other changes in practice were planned, or occurred, within the study timescales and hence it was assumed that any change was a result of the educational intervention. 


\section{Results}

The baseline assessment included 301 imaging examinations, comprising 242 wrist and 59 scaphoid series. When the images were reviewed for position, 42 examinations were excluded as the anatomy was obscured because of a cast $(n=33)$ or recent surgery $(n=9)$. Additionally, other examinations were excluded as the ulna could not be visualised $(n=9)$, the ulna styloid was nonossified making evaluation difficult $(n=6)$, the anatomy had been excluded from the image on one projection $(n=3)$ or the fracture fragments $(n=2)$ made assessment challenging. The exclusions resulted in a final sample of 239 examinations performed by a total of 108 individuals.

The early and late phase evaluations comprised 221 and 168 examinations respectively. Characteristics of the three phases are summarised in table 1.

Table 1: Sample characteristics across each phase

\begin{tabular}{|l|l|l|l|l|l|}
\hline \multirow{2}{*}{ Referral route } & \multicolumn{2}{|l|}{ Clinical History } & Total \\
referrals & $\begin{array}{l}\text { Excluded } \\
\text { from } \\
\text { review }\end{array}$ & $\begin{array}{l}\text { Total } \\
\text { reviewed }\end{array}$ \\
\cline { 2 - 6 } & Trauma & Other & 175 & 18 & 157 \\
\hline Emergency Department & 167 & 8 & 26 & - & 26 \\
\hline Primary care & 10 & 16 & 1 & - & 1 \\
\hline Inpatient & - & 1 & 18 & 45 & 54 \\
\hline Outpatient & 72 & 27 & 99 & $\mathbf{6 3}$ & $\mathbf{2 3 8}$ \\
\hline Total & $\mathbf{2 4 9}$ & $\mathbf{5 2}$ & $\mathbf{3 0 1}$ & & \\
\hline
\end{tabular}

Similarity between the three samples was confirmed in relation to age $(p=0.037)$, and importantly there was no significant difference in the proportion of referrals routes $(p=0.816)$ or the number of examinations excluded during the initial screening $(p=0.187)$

Across the study phases only a minority of radiographs demonstrated compliance with the standard technique. Rather than demonstrating a difference in the ulna position between the PA and lateral projections (Figure 1) there was an identical anatomical appearance (Figure 2). 


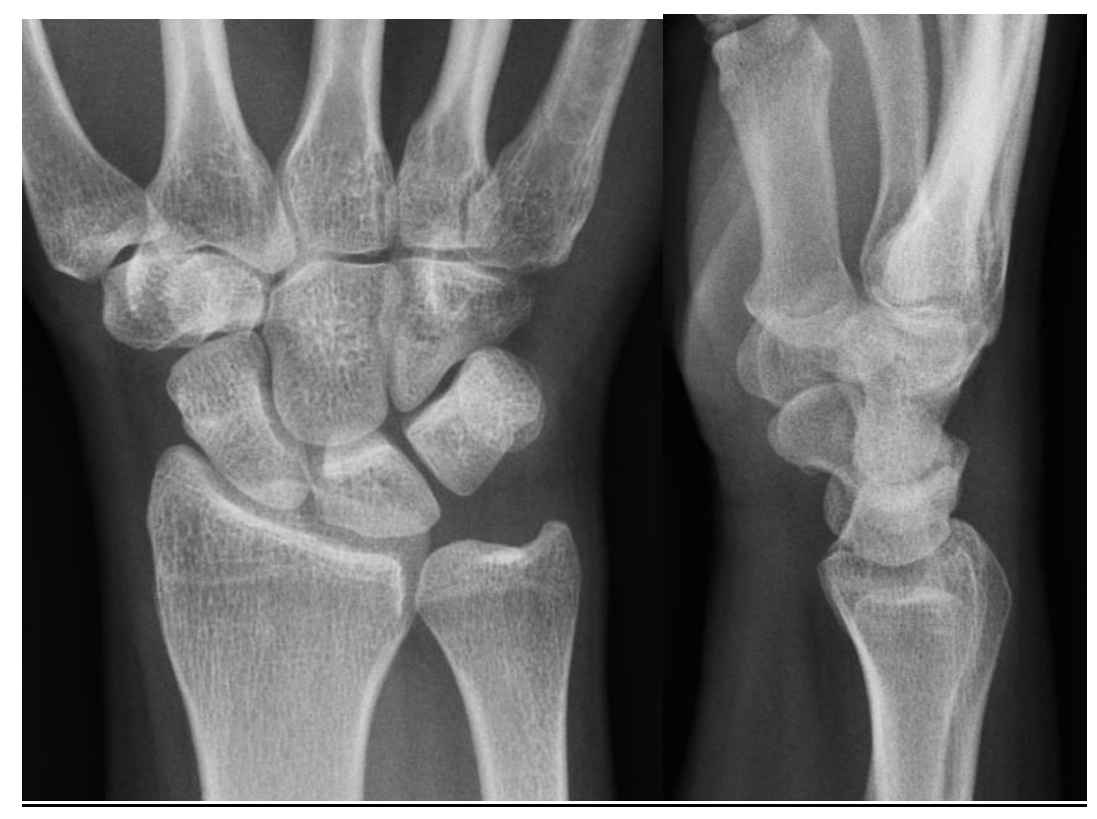

Figure 1: Collimated example wrist radiographs (1a PA and 1b lateral) demonstrating compliance with the expected standard

NB. Note the difference in orientation of the distal ulna

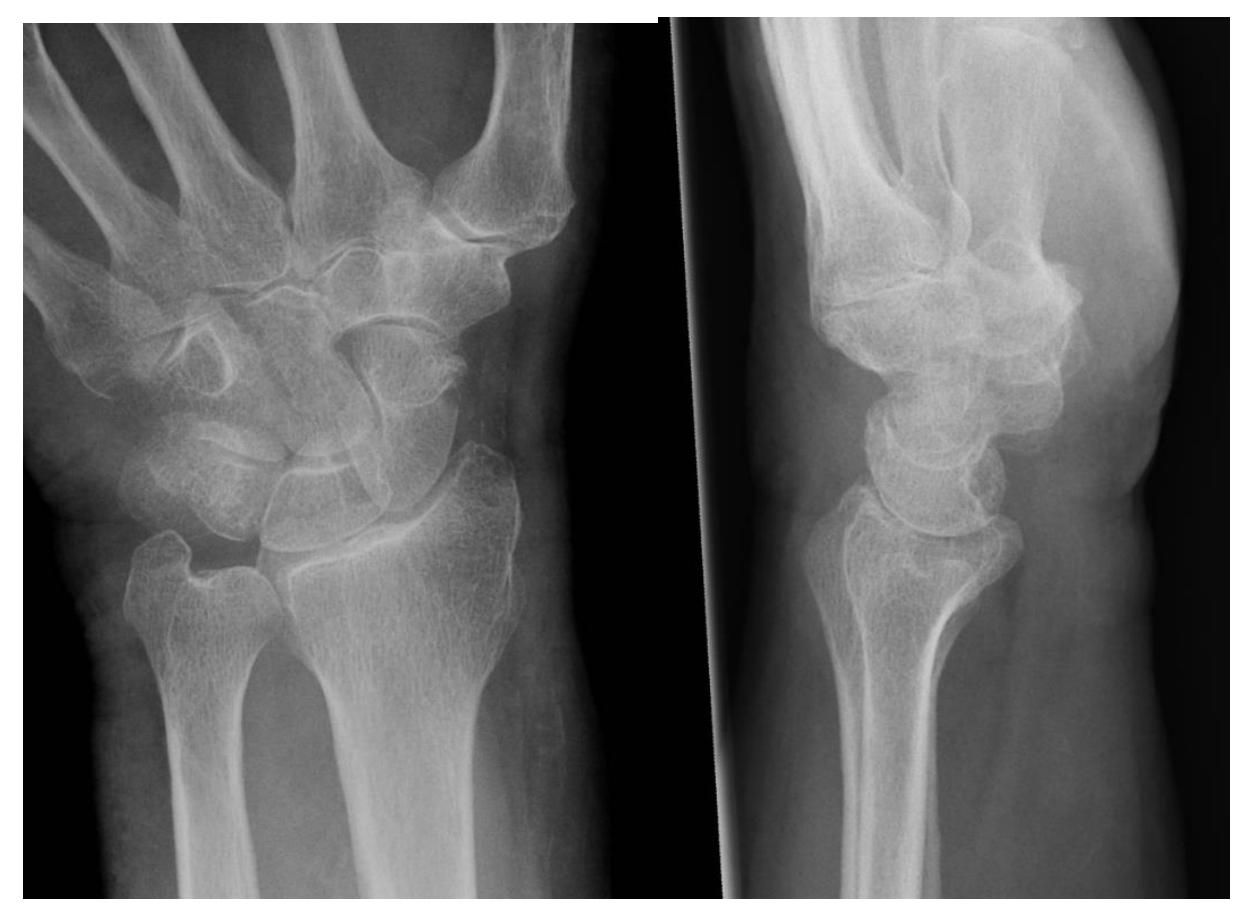

Figure 2: Collimated example wrist radiographs (2a PA and $2 \mathrm{~b}$ lateral) demonstrating non-compliance with the expected standard

NB. Note the same appearance of the distal ulna and styloid process 
Clinical history appeared not to influence the positioning of the wrist, with no significant difference in compliance with the standard across patients with acute trauma $(n=24 / 159)$ compared to those without any recent trauma $(n=7 / 44)$ in the baseline sample $(p=0.894)$. In contrast, the presence of pathology did appear to influence practice with a greater proportion of those with an abnormal radiographic examination demonstrating a change in ulna appearances in the baseline cohort $(p<0.001)$, this was also found in the late post-intervention group $(p=0.002)$ but not in the examinations performed 2 -weeks after staff education $(p=0.239)$.

A positive impact of the intervention was noted after implementation, although this only reached significance at a number of the sites (Table 2). There was an overall significant drop off in compliance over time $(p=0.011)$, but this again varied across the hospital sites.

Table 2: Comparison of compliance with standard positioning across sites pre and post-intervention

\begin{tabular}{|c|c|c|c|c|c|c|}
\hline \multirow[b]{3}{*}{ Site } & \multicolumn{6}{|c|}{ Phase } \\
\hline & \multicolumn{2}{|c|}{$\begin{array}{l}\text { Pre-intervention } \\
\text { (baseline) }\end{array}$} & \multicolumn{2}{|c|}{$\begin{array}{l}\text { Early post-intervention } \\
\text { ( } 2 \text { weeks) }\end{array}$} & \multicolumn{2}{|c|}{$\begin{array}{l}\text { Late post-intervention } \\
\text { (3-months) }\end{array}$} \\
\hline & $\begin{array}{l}\text { Sample } \\
\mathbf{n}\end{array}$ & $\begin{array}{l}\text { Compliance } \\
\text { n (\%) }\end{array}$ & $\begin{array}{l}\text { Sample } \\
\mathbf{n}\end{array}$ & $\begin{array}{l}\text { Compliance } \\
\text { n (\%) }\end{array}$ & $\begin{array}{l}\text { Sample } \\
\mathbf{n}\end{array}$ & $\begin{array}{l}\text { Compliance } \\
\text { n (\%) }\end{array}$ \\
\hline A & 21 & 4 (19.0) & 15 & 7 (46.7) & 17 & $7(41.2)$ \\
\hline B & 36 & $9(25.0)$ & 18 & $9(50.0)$ & 12 & $4(33.3)$ \\
\hline D & 13 & $3(23.1)$ & 26 & $12(46.2)$ & 18 & $5(27.8)$ \\
\hline $\mathbf{E}$ & 39 & $2(5.1)$ & 29 & $13(44.8)^{*}$ & 18 & $8(44.4)$ \\
\hline $\mathbf{F}$ & 35 & $-(0.0)$ & 8 & $5(62.5)^{*}$ & 12 & $6(50.0)$ \\
\hline G & 27 & $4(14.8)$ & 22 & $14(63.6)^{*}$ & 12 & $4(33.3)$ \\
\hline $\mathbf{I}$ & 28 & $6(21.4)$ & 20 & $8(40.0)$ & 16 & $4(25.0)$ \\
\hline J & 39 & $12(30.8)$ & 23 & 9 (39.1) & 20 & $3(15.0)$ \\
\hline Total & 238 & $40(16.8)$ & 161 & $77(47.8)^{*}$ & 125 & $41(32.8)^{*}$ \\
\hline
\end{tabular}

\section{Discussion}

The study highlights important outcomes, particularly where the review of wrist imaging underpins clinical management plans. Knowledge of radiographic anatomical appearances is critical for diagnosis and treatment planning. Despite UK radiography education and text books ${ }^{14,15}$ demonstrating imaging techniques designed to produce orthogonal projections it is clear this is not embedded in practice. The poor compliance with the standard may be exacerbated as some imaging texts describe the maintenance of elbow flexion between projections. ${ }^{16-19}$ Although some books describe both techniques, ${ }^{20,21}$ only one providing justification for the use of the orthogonal projection. ${ }^{21}$

The sampling strategy and number of staff involved during each phase of the study affirms that the findings are not biased by only the inclusion of a few individuals. Despite most referrals within the evaluation period being post-trauma, radiographers were able to influence the patients to supinate the forearm. This resulted in lateral projections with a change in the radial, but not the ulna, orientation. As acknowledged by Steward and Peacock ${ }^{11}$ in the post-injury imaging examination this 
may result in increased pain and discomfort as the muscles contract during rotation, potentially displacing fracture fragments. Importantly, examinations demonstrating abnormal findings were more likely to have a change in ulna appearance, and therefore arm position. It is presumed that this is because the patient maintained the neutral wrist position with full extension of the arm for the lateral projection. Although, it may be because the radiographer had adapted the technique to account for potential pain and/or a reduced range of movement. The ability to maintain forearm rotation with a displaced distal radial fracture has been previously confirmed, ${ }^{22}$ however research findings are inconsistent. ${ }^{23,24}$ It is suggested that disruption to the triangular fibrocartilage complex (TFCC) releases the DRUJ tether and enables functional motion at this site. ${ }^{22,24}$

Although the forearm appears to comprise parallel and somewhat rigid bony structures, the radius and ulna actually rotate independent of each other. ${ }^{25,26}$ The radiographic positioning has implications for the diagnosis of injuries with images demonstrating two identical ulna projections reducing the potential for fracture identification. Importantly, supination and pronation movements stress the different ligamentous complexes involved in the DRUJ and will alter the biomechanics and potentially mimic or hide soft tissue disruption at this site. Additionally, measurement of ulna variance, an abnormally short or elongated ulna, relies on the maintenance of neutral wrist position as pronation and supination vary the length of the ulna, even marginally. ${ }^{12,27}$

It is unclear what the reason is behind the change in radiographic principles away from orthogonal projections, although this has been recognised by other authors. ${ }^{8,9,12-14}$ The speed of image acquisition in the digital age and limited knowledge of functional anatomy may both play a part. Radiography is one of the easiest examinations to control the wrist position. Despite the superiority in diagnostic ability both multidetector computed tomography (CT) and magnetic resonance imaging ( MRI) examinations require the arm to be outstretched above the head (AKA the prone 'superman') or placed by the patients side, ${ }^{28}$ which will usually induce some supination of the forearm. This is not the case for extremity cone-beam CT which usually enables the patient to be seated with their arm placed in the scanner gantry. ${ }^{6}$ It is therefore important that those reviewing cross-sectional imaging understand the impact of the issues. This is particularly relevant where DRUJ congruity is being assessed and specifically when comparing studies which may have been obtained in different positions. ${ }^{13}$

Previous studies have examined the use of educational interventions to improve compliance with clinical practice standards, ${ }^{29-32}$ particularly medication administration errors, ${ }^{33}$ although radiography examples are limited. ${ }^{34,35}$ It is recognised that quality assurance processes are used within imaging departments and improvement strategies are employed, but these appear to be focussed at a local level. The choice of a low intensity intervention enabled a broad reach across multiple sites simultaneously and did not rely on individual attendance at a teaching session. Lecture-based education has limitations, including poor retention of information, in addition to challenges of attendance and delivery patterns. ${ }^{29}$ As educational posters also are available over an extended period of time it was also hoped that it could serve as a reminder for staff, supporting retention of knowledge. Although the overall improvement was initially significant, the impact was seen to vary across hospital sites, however the reason for this was not investigated further. It was disappointing that the benefit was not sustained, with some sites reverting to the pre-intervention compliance, or even lower. This failure to sustain change on the back of an educational intervention is consistent with other studies ${ }^{29}$ although the outcomes did prove more successful than other programmes. ${ }^{32}$ 
The use of multi-modal initiatives may help embed the principles of patient positioning, particularly the addition of simulation.

There are a number of limitations to this study. Firstly, the review of the images was undertaken by a single (different) investigator at each site, although they utilised a standard process following group training to minimise variation. The number of days reviewed in each phase varied and was undertaken over a different time period. The number of examinations reviewed and staff involved in the imaging should reduce the potential for bias from any sampling differences. The images were assessed retrospectively solely for the orientation of the ulna and no observation of patient positioning was undertaken. The literature highlights several potential issues with radiographic positioning, however this study only sought to assess the single issue and differing standards may be taught and deemed acceptable internationally. Importantly, the implications of the differences in wrist positioning on clinical decision making and patient outcomes has not been evaluated and requires prospective investigation.

\section{Conclusion}

This study has confirmed that imaging acquisition techniques adopted by clinical staff with resultant implications for anatomical representation. Clinicians using wrist imaging for clinical diagnosis and treatment monitoring should be aware of how to assess the quality of the images and consider the implications of imaging techniques on decision making.

A simple educational intervention provided a transient improvement in compliance with the accepted technique parameters, but the impact was not sustained over time. Further multi-modal interventions including simulation may assist in cultural change, as it requires a fundamental challenge to knowledge of patient positioning and functional anatomy.

\section{References}

1. Haugstvedt JR, Langer MF, Berger RA. Distal radioulnar joint: functional anatomy, including pathomechanics.J Hand Surg Eur Vol 2017, Vol. 42E(4) 338-345

2. Chen YR, Tang JB. In Vivo Gliding and Contact Characteristics of the Sigmoid Notch and the Ulna in Forearm Rotation. J Hand Surg Am 2013; 38A: 1513-9.

3. DiTano $O$, Trumble TE, Tencer AF. Biomechanical function of the distal radioulnar and ulnocarpal wrist ligaments. J Hand Surg Am 2003; 28A: 622-7

4. McIntyre NJ, Dewan N. Epidemiology of distal radius fractures and factors predicting risk and prognosis. J Hand Ther 2016; 29: 136-45.

5. Nellans KW, Olson PR, Rosenwasser MP. The epidemiology of distal radius fractures. Hand Clinics 2012; 28: 113-25.

6. Gibney B, Smith M, Moughty A, Kavanagh EC, Hynes D, MacMahon PJ. Incorporating cone-beam $\mathrm{CT}$ into the diagnostic algorithm for suspected radiocarpal fractures: A new standard of care? AJR 2019; 213: 1117-23.

7. Balci A, Basara I, Çekdemir EY, Tetlik F, Aktaş G, Acarer A, Özaksoy D. Wrist fractures: sensitivity of radiography, prevalence, and patterns in MDCT. Emerg Radiol 2015; 22:251-256 
8. Hardy DC, Totty WG, Reinus WR, Gilula LA. Posteroanterior wrist radiography: Importance of arm positioning. J Hand Surg 1987; 12A: 504-8.

9. Touquet $R$, Driscoll $P$, Nicholson $D$. Teaching in accident and emergency medicine: 10 commandments of accident and emergency radiology. BMJ 1995; 310: 642-5

10. Bhat AK, Kumar B, Acharya A. Radiographic imaging of the wrist. Indian J Plast Surg 2011; 44: 186-96.

11. Steward AL, Peacock NE. Alternative positioning approach to a true lateral wrist. Radiol Technol 2019; 90: 625-32.

12. Epner RA, Bowers WH, Bonner Guilford W. Ulnar variance - the effect of wrist positioning and roentgen filming technique. J Hand Surg 1982; 7: 298-305.

13. Shin S-H, Lee Y-S, Kang J-W, et al. Where Is the Ulnar Styloid Process? Identification of the Absolute Location of the Ulnar Styloid Process Based on CT and Verification of Neutral Forearm Rotation on Lateral Radiographs of the Wrist. Clin Orthop Surg 2018; 10: 80-8.

14. Carver E, Carver B. Medical imaging: techniques, reflection and evaluation. $2^{\text {nd }}$ edn. Edinburgh: Elsevier. 2012.

15. Whitley AS, Jefferson G, Holmes K, Sloane C, Anderson C, Hoadley G. Clark's positioning in radiography $13^{\text {th }}$ edn. CRC Press. 2015.

16. Long BW, Rollins JH, Smith BJ. Merrill's atlas of radiographic positioning and procedures $14^{\text {th }}$ edn. St Louis: Elsevier. 2019.

17. Lampignano JP, Kendrick LE. Bontrager's handbook of radiographic positioning and techniques $9^{\text {th }}$ edn. St Louis: Mosby. 2017.

18. Greathouse JS, Adler AM, Carlton R. Principles of radiographic positioning and procedures pocket guide. Stanford: Cengage Learning. 2015.

19. Sutherland R, Thomson C. Pocketbook of radiographic positioning $3^{\text {rd }}$ edn. Edinburgh: Churchill Livingstone. 2007.

20. Sloane C, Holmes K, Anderson C, Whitley AS. Clark's pocket handbook for radiographers. London: Hodder Arnold. 2010.

21. McQuillen-Martensen K. Radiographic critique. Philadelphia: Saunders. 1996.

22. Fraser GS, Ferreira LM, Johnson JA, King GJW. The effect of multiplanar distal radius fractures on forearm rotation: In vitro biomechanical study. J Hand Surg Am 2009; 34A: 838-48.

23. Ishikawa J, Iwasaki N, Minami A. Influence of distal radioulnar joint subluxation on restricted forearm rotation after distal radius fracture. J Hand Surg Am 2005; 30A: 1178-84.

24. Nishikawa M, Welsh MF, Gammon B, Ferreira LM, Johnson JA, King GJW. Effect of volarly angulated distal radius fractures on forearm rotation and distal radioulnar joint kinematics. $J$ Hand Surg Am 2015; 40: 2236-42.

25. Soubeyrand M, Assabah B, Bégin M, Laemmel E, Dos Santos A, Crézé M. Pronation and supination of the hand: Anatomy and biomechanics. Hand Surg Rehabil 2017; 36: 2-11

26. Buck FM, Nico MAC, Gheno R, Haghighi P, Trudell DJ, Resnick D. Morphology of the distal radioulnar joint: cadaveric study with $M R I$ and $M R$ arthrography with the forearm in neutral position, pronation, and supination. AJR 2010; 194:W202-7.

27. Bernstein DT, Linnell JD, Peterson NJ, Netscher DT. Correlation of the lateral wrist radiograph to ulnar variance: a cadaveric study. J Hand Surg Am 2018; 43: 951.e1-e9.

28. Dick EA, Burnett C, Gedroyc WMW. MRI of the wrist. Radiography 2008; 14: 246-54. 
29. Kempegowda $P$, Chandan JS, Hutton $R$, et al. Focused educational intervention improves but may not sustain knowledge regarding falls management. BMJ Open Quality 2018;7:e000222. doi:10.1136/bmjoq-2017-000222

30. Maher PJ, Brown AEC, Gatewood MO. The effect of written posted instructions on collection of clean-catch urine specimens in the emergency department. J Emerg Med 2017;52:639-44.

31. Thomas JS, Gillard D, Khor M, Hakendorf P, Thompson CH. A comparison of educational interventions to improve prescribing by junior doctors. Q J Med 2015; 108: 369-77 doi:10.1093/qjmed/hcu213

32. Morse L. McDonald M. Failure of a poster-based educational programme to improve compliance with peripheral venous catheter care in a tertiary hospital. A clinical audit. J Hosp Inf 2009; 72: 221-6.

33. Berdot S, Roudot M, Schramm C, Katsahian S, Duriex P, Sabatier B. Interventions to reduce nurses' medication administration errors in inpatient settings: A systematic review and metaanalysis. Int J Nurs Stud 2016; 53: 342-50.

34. Richards B, Riley J, Saithna A. Improving the diagnostic quality and adequacy of shoulder radiographs in a District General Hospital. BMJ Quality Improvement Reports 2016; 5:u209855.w3501. doi:10.1136/bmjquality.u209855.w3501

35. Calabrese I, Fuller M, Chau M, Parange N. A pilot study to examine the effect of an educational poster on the knowledge and practices of lateral elbow radiograph repositioning in radiographers. Journal of Medical Imaging and Radiation Sciences. DOI: https://doi.org/10.1016/j.jmir.2019.11.003

\section{Tables and Figures}

Table 1: Phase 1 sample and review characteristics

Figure 1: Collimated example wrist radiographs (1a PA and 1b lateral) demonstrating compliance with the expected standard

Figure 2: Collimated example wrist radiographs (2a PA and $2 \mathrm{~b}$ lateral) demonstrating non-compliance with the expected standard

Table 2: Comparison of compliance with standard positioning across sites pre and post-intervention 